This is the author's final, peer-reviewed manuscript as accepted for publication. The publisher-formatted version may be available through the publisher's web site or your institution's library.

\title{
Developmental and environmental effects on the assembly of glutenin polymers and the impact on grain quality of wheat
}

\author{
H. A. Naeem, D. Paulon, S. Irmak and F. MacRitchie
}

\section{How to cite this manuscript}

If you make reference to this version of the manuscript, use the following information:

Naeem, H. A., Paulon, D., Irmak, S., \& MacRitchie, F. (2012). Developmental and environmental effects on the assembly of glutenin polymers and the impact on grain quality of wheat. Retrieved from http://krex.ksu.edu

\section{Published Version Information}

Citation: Naeem, H. A., Paulon, D., Irmak, S., \& MacRitchie, F. (2012). Developmental and environmental effects on the assembly of glutenin polymers and the impact on grain quality of wheat. Journal of Cereal Science, 56(1), 51-57.

Copyright: () 2012 Elsevier Ltd.

Digital Object Identifier (DOI): doi:10.1016/j.jcs.2011.10.014

Publisher's Link: http://www.sciencedirect.com/science/article/pii/S0733521012000513

This item was retrieved from the K-State Research Exchange (K-REx), the institutional repository of Kansas State University. K-REx is available at http://krex.ksu.edu 


\title{
Developmental and environmental effects on the assembly of glutenin polymers and the impact on grain quality of wheat
}

\author{
H.A. Naeem ${ }^{1}$, D. Paulon ${ }^{2}$, S. Irmak ${ }^{3}$ and F. MacRitchie ${ }^{4}$ \\ ${ }^{1}$ Agroforestry Development Centre, Indian Head SK Canada. \\ ${ }^{2} 88$ Coral Gable Drive, Toronto ON, M9M 1P1, Canada. \\ ${ }^{3}$ Department of Chemistry, Cukurova University, Balcali, Adana 01330, Turkey. \\ ${ }^{4}$ Department of Grain Science \& Industry, Kansas State University, Manhattan, Kansas USA.
}

\begin{abstract}
Abbreviations: AFFFF, asymmetric flow field flow fractionation; DAA, days after anthesis; HMW-GS, high molecular weight glutenin subunits; LMW-GS, low molecular weight glutenin subunits; MALLS, multi-angle laser light scattering; SE-HPLC, size-exclusion high performance liquid chromatography; UPP, unextractable polymeric protein.

* Corresponding author. Agroforestry Development Centre, P.O. Box 940, Indian Head, S0G 2K0 Canada. Tel.:+1 306695 5127; fax: +1 3066952568.

E-mail address: Hamid.Naeem@gmail.com (H.A. Naeem).
\end{abstract}

\section{Abstract}

Wheat kernel development can be divided into three phases i.e. cell division, cell enlargement and dehydration. Accumulation of gluten proteins continues till the end of the cell enlargement phase. During the dehydration phase, post-translational polymerization of the glutenin subunits occurs to form very large glutenin polymers. Assembly of the glutenin polymers has been monitored by increase in the unextractable polymeric protein. Lines possessing HMW-GS related to dough strength (e.g. 5+10) started accumulating large polymers several days earlier than lines with HMW-GS related to dough weakness (e.g. 2+12) and maintained their higher amounts till maturity. This may be explained by faster polymerization resulting from a higher concentration of cysteine residues in the x-type HMW-GS.

Sulphur deficiency leads to an increase in the ratio of HMW- to LMW-GS, causing a shift in the MWD to higher MWs, resulting in bucky dough properties. High temperature during grain development appears to shift the MWD to lower MWs with corresponding lowering of dough strength but the presence of strength-associated HMW-GS appears to confer greater tolerance to heat stress. Since sulphur deficiency and higher global temperatures may be expected to increase in the future, some suggestions how breeders may use strategies to counter these effects are put forward. 


\section{Introduction}

\subsection{Background}

In recent times, there have been an increasing number of studies of the changes in composition of the wheat kernel during its development (Benetrix et al., 1994; Daniel and Triboï, 2002; Dupont et al., 1998; Gobin et al., 1997; Gupta et al., 1996; Huebner et al., 1990; Johansson et al., 1994; Panozzo et al., 2001; Shewry et al., 2009; Stone and Nicolas, 1996a). Studies that have focused particularly on glutenin polymerization during grain development include those of Carceller and Aussenac (1999), Zhu and Khan (1999) and Naeem and MacRitchie (2005). The work up until 2003 was thoroughly reviewed by Dupont and Altenbach (2003). A rationale for this work is that quality cannot be fully understood by studies of the mature grain alone. During grain filling, genetic and environmental effects change the composition, in particular that of the proteins, in ways that influence the final quality. Understanding how these changes occur can help in the design of strategies for manipulating them to target the end-use properties that are sought. The balance of proteins, especially the gluten proteins, is responsible for physical properties such as dough strength, extensibility and expansion capacity of the dough in baking. Two main variables determine these properties, namely (a) the ratio of polymeric proteins (mainly glutenins) to monomeric proteins (gliadins) and (b) the molecular weight distribution (MWD) of the polymeric proteins. The former is determined largely by genetic factors; i.e. approximately the numbers of genes coding for gliadins and for glutenin subunits. The large glutenin polymers are made up of two main groups of subunits, the high molecular weight (HMWGS) and the low molecular weight (LMW-GS) subunits. In this article, we will mainly focus on the second variable. The MWD of glutenin is influenced by both genetic and environmental factors.

\subsection{Genetic control of gluten proteins}

Fig. 1 shows a schematic and simplified representation of the chromosomal location of the genes coding for the gluten proteins (MacRitchie and Lafiandra, 1997). Glutenin subunits are coded at loci on group 1 chromosomes, the HMW-GS at the Glu-1 loci on the long arms, and the LMWGS at the Glu-3 loci on the short arms. Two HMW-GS may be expressed at each of the three Glu-1 loci, denoted as x subunits (lower electrophoretic mobility) and y subunits (higher electrophoretic mobility). For common cultivars, it is found that, although both subunits are expressed at Glu-D1, one or both may be expressed at Glu-B1 and one or zero at Glu-A1. The $\gamma-$ and $\omega$-gliadins are coded by genes at loci (Gli-1) on the short arms of group 1 chromosomes. These genes are tightly linked to the genes coding for LMW-GS at Glu-3. The $\alpha$ - and $\beta$-gliadins, now considered to be one group (Shewry et al., 1986), are coded by genes at the Gli-2 loci on the short arms of group 6 chromosomes.

If these gene products (gliadins and glutenin subunits) were the only distinct compounds present in mature grain, wheat would not be the widely grown crop that is prized for its numerous consumer favoured products. Many of these products, particularly aerated ones, depend on the capacity of wheat flour or meal to form dough with viscoelastic properties. This capacity makes it ideally suited to incorporate stable gas bubbles that expand during processing to give light palatable products. The property of acquiring viscoelastic dough properties only arises because 
of a post-translational polymerization of the glutenin subunits to form very large glutenin polymers. These large glutenin polymers are responsible for the strength and elasticity of wheat flour dough.

\section{Experimental procedures}

Measuring the composition of developing kernels is a demanding experimental procedure and requires close attention to detail in order to ensure reliable results. It begins with planting (field or greenhouse) and watering and fertilizing the plants during the growing period, which usually takes several weeks. Field studies are subject to the unexpected variations of weather, although some control can be exercised; e.g. by watering during spells of dry weather. Since these experiments often require replicate measurements in different seasons, it is important to monitor conditions (e.g. temperature, relative humidity, rainfall, wind speed) in the different seasons so as to at least be able to attempt to rationalize results due to seasonal variations. Greenhouse and growth chambers are more amenable to controlling the conditions. Temperature should be controlled and plants watered sufficiently to prevent moisture stress. It should always be kept in mind that what happens in the greenhouse is not always correlated with what happens in the field. Therefore, where possible, greenhouse studies should be corroborated by follow up field studies.

When plants flower, spikes are tagged on the day flowering begins. The time of flowering may vary between spikes from the same plant and indeed from seeds from the same spike. To allow for this, seeds are often collected from the centre of the spike. The immature kernels are collected at determined intervals, immediately frozen in liquid nitrogen to terminate metabolic processes and then placed in labeled containers. The material is threshed and the grain is freezedried prior to grinding to a powder, sufficiently fine to pass through a sieve of about $130 \mathrm{~mm}$, preparatory to analysis.

\subsection{Methods for monitoring glutenin polymerization during grain filling}

\subsubsection{Absolute methods}

The polymerization of glutenin subunits begins at an intermediate period between anthesis and maturity and proceeds up to maturity. To follow the process requires a method to measure the MWD of glutenin and the method needs to be one capable of measuring the MW of large molecules, in the order of millions. Methods that have been used include absolute methods for MW determination as well as methods based on solubility (Gupta et al., 1993) and on electrophoretic mobility (Zhu and Khan, 1999). Rhazi et al. (2003) have used asymmetrical flow field flow fractionation (AFFFF) in combination with multi-angle laser light scattering (MALLS), based on an earlier method using size-exclusion high performance liquid chromatography-MALLS developed by Carceller and Aussenac (2001). This enabled measurements of both molecular size (number-average and weight-average MW) and conformation (weight-average mean square radius) of polymeric protein from ground kernels of the cultivars Soissons and Thésée, grown at a number of locations. AFFFF and MALLS have the advantage that they are absolute methods. On the other hand, they depend on having all the protein in solution and this can present a challenge. Unfortunately, no method for complete 
solubilization of wheat glutenin has been discovered without altering the protein. Solubilization can be achieved using chemical reducing agents to break all the disulphide bonds or sonication to break disulphide bonds of the largest glutenin molecules, thus altering the MWD.

\subsubsection{Methods based on solubility}

The failure to completely solubilize glutenin has been made use of to devise a method to obtain relative measurements of MWD. Although not an absolute method, it has proved very convenient for monitoring the polymerization of glutenin during grain development. The preferred solvent has been dilute sodium dodecyl sulphate (SDS). The theoretical basis of the method is that there is an inverse relationship between MW and solubility. The insoluble portion of polymeric protein has been termed either the unextractable polymeric protein (UPP) (Gupta et al., 1993) and sometimes the insoluble polymeric protein (IPP) or the glutenin macropolymer (GMP) (Weegels et al., 1996). These essentially measure the same parameter. Both terms are acceptable and have been widely used. We prefer to use the term UPP as the parameter is based on an empirical measurement. The polymeric protein fraction that is insoluble (unextractable) is not a specific component but contains varying mixtures of all the proteins in the heterogeneous sample with a heavy weighting towards the larger molecular components. This fraction can be quantified either by solubilization followed by sonication of the residue and analysis by sizeexclusion high-performance liquid chromatography (SE-HPLC) (Gupta et al., 1993) or by simple direct analysis of the insoluble residue (Bean et al., 1998).

\subsubsection{Theoretical basis of UPP}

When two components are mixed to form a solution, the solubility of one (solute) in the other (solvent) depends on the change in free energy of solution $\left(\Delta \mathrm{G}_{\text {soln }}\right)$ which can be written as:

$\Delta \mathrm{G}_{\mathrm{soln}}=\Delta \mathrm{H}_{\mathrm{soln}}-\mathrm{T} \Delta \mathrm{S}_{\mathrm{soln}}$

where $\Delta \mathrm{H}_{\text {soln }}=$ enthalpy of solution, $\Delta \mathrm{S}_{\text {soln }}=$ entropy of solution and $\mathrm{T}=$ absolute temperature (K).

The solute will begin to dissolve in the solvent if $\Delta \mathrm{G}_{\text {soln }}$ is negative until saturation is reached, when further dissolution will not further lower $\Delta \mathrm{G}_{\text {soln. }}$. A perfect solution is defined as one in which $\Delta \mathrm{H}_{\text {soln }}$ is zero and the size and shape of solute and solvent molecules are equal. Under these conditions, $\Delta \mathrm{G}_{\text {soln }}$ is given exactly by $-\mathrm{T} \Delta \mathrm{S}_{\text {soln }}$ where $\Delta \mathrm{S}_{\text {soln }}$ is simply the entropy of mixing of solute and solvent molecules. This will have a negative value for all ratios of solute to solvent and thus solute and solvent will be miscible in all proportions. For solutions that are not perfect, there will be other contributions to $\Delta \mathrm{G}_{\text {soln }}$ because of deviations of $\Delta \mathrm{H}_{\text {soln }}$ and $\Delta \mathrm{S}_{\text {soln }}$ from perfect behaviour. This may lead to only partial miscibility as is the case for aqueous solutions of gluten proteins. Nevertheless, the entropy of mixing will still make an important contribution to the free energy of solution and thus the solubility. The entropy of mixing is a function of the number of ways of arranging molecules of solute and solvent (see MacRitchie, 2010). It is a maximum when solute and solvent molecules are the same size and shape. As the size of protein molecules increases, the number of arrangements and thus the entropy of mixing, correspondingly decreases and its contribution to $\Delta \mathrm{G}_{\text {soln }}$ also decreases. This therefore leads to an inverse relationship between solubility and molecular size: 


$$
\text { Solubility }=f(1 / \mathrm{MW})
$$

\section{Polymerization studies of glutenin during grain development. Genetic effects}

\subsection{Different stages of grain development}

A number of studies have been made of the accumulation of different protein classes during grain development (Benetrix et al., 1994; Daniel and Triboï, 2002; Gobin et al., 1997; Huebner et al., 1990; Johansson et al., 1994; Panozzo et al., 2001; Stone and Nicolas, 1996a). Three main stages of developing grain have been described by Carceller and Aussenac (1999) and these are illustrated in Fig. 2, in terms of days after anthesis (DAA). For the conditions shown in Fig. 2 for two cultivars, the first stage ( 0 - 20 DAA) represents cell division, the second stage (20 - 33 DAA) is the cell enlargement phase and 33 DAA and beyond corresponds to dehydration and grain maturation. It should be noted that the DAA times are specific for the conditions and that degree days is a more precise parameter. Accumulation of albumins/globulins increases during cell division but reaches a plateau in the cell division stage. The gluten proteins (gliadins and glutenins) increase up to the end of cell enlargement. Towards the end of the cell enlargement stage, the UPP begins to increase and rises steeply during the dehydration stage up to close to maturity, indicating that large glutenin polymers are being formed (Carceller and Aussenac, 1999).

\subsection{Allelic effects in polymerization}

Most studies of the polymerization of glutenin during grain filling have used measurements of UPP to monitor progress. Carceller and Aussenac (1999) compared protein composition of two cultivars, Soissons of good bread-making quality and Thésée, of poor quality. The HMW-GS compositions of these cultivars were: Soissons $(2 *, 7+8,5+10)$ and Thésée (null, $6+8,2+12)$. During grain filling, the UPP of both cultivars began to increase during the desiccation stage but, for Soissons, it increased more steeply and reached a higher value than for Thésée at maturity. The superiority of the Glu-D1d (HMW-GS 5+10) allele over the Glu-D1a (HMW-GS 2+12) allele in terms of dough strength has been well established since the work of Payne and coworkers (e.g. Payne et al., 1981). A greater understanding of the basis of these differences has emerged from a study by Gupta and MacRitchie (1994). A comparison between allelic variants (Glu-D1d or Glu-D1a) in pairs of near-isogenic lines of three cultivars showed that dough strength, measured by mixograph dough development time, was not related to the total protein or polymeric protein content but was highly correlated with UPP. Thus, the greater strength of the lines having the Glu-D1d locus could be explained by a MWD shifted to higher values when HMW-GS $5+10$ were present than when HMW-GS $2+12$ were present. The advantage in using near-isogenic lines is that differences due to other sources of genetic variation that may contribute when comparing unrelated cultivars, are minimized. The use of field-grown nearisogenic lines differing at Glu-D1 (Lance C and Lance A) in a study of grain development by Gupta et al. (1996) showed that the line having the Glu-D1d allele (HMW-GS 5+10) increased in UPP at an earlier stage (by about 3 days) than the line with the Glu-D1a allele (HMW-GS 2+12) and maintained the higher UPP value until maturity. These results were confirmed by Paulon 
(2000), using the same two lines grown under greenhouse conditions. The work was extended by Naeem and MacRitchie (2005) in both greenhouse and field conditions to examine the behaviour of three pairs of near-isogenic lines of the varieties Lance, Avocet and Warigal, each differing at Glu-D1. The behaviour was consistent for the three pairs and is illustrated in Fig. 3 for the variety Avocet, grown in the greenhouse. It is seen that the UPP of the line having the Glu-D1d allele begins to increase at an earlier time (several days) than the line with the Glu-D1a allele and reaches a higher value at maturity. The mixograph peak dough development times of flours from mature grain of the lines with the Glu-D1d allele were all greater than those from the lines with the Glu-D1a allele. In addition, two near-isogenic lines of the variety Halberd differing at Glu-B1 were used. Halberd A had HMW-GS composition $(1,7+9,5+10)$ and Halberd B had (1, $20 x+20 y, 5+10)$. The subunit pair $7+9$ has been associated with dough strength and the subunit pair $20 x+20 y$ with weak dough properties. Similar to the Glu-D1 allelic variants, the Halberd line with the strength-associated HMW-GS $7+9$ showed an earlier increase of UPP during grain filling and a higher UPP at maturity than the line with HMW-GS 20x+20y. Thus, we can conclude that earlier polymerization and higher MWD at maturity is a general attribute related to the presence of strength-associated HMW-GS. It should be made clear that, in all the studies mentioned, there were no significant differences in the total amounts of polymeric protein between either the Soissons and Thésée lines or individual lines of the pairs of near-isogenic lines, measured by size-exclusion liquid chromatography (SE-HPLC).

\subsection{The role of the desiccation phase}

Those researching the topic of grain development have sought to understand the process of posttranslational polymerization of glutenin subunits to form the large glutenin polymers. Some progress has been made as a result of the work of Aussenac and coworkers (e.g. Carceller and Aussenac, 1999). They noted that the most rapid formation of SDS-insoluble polymers coincided with the period of rapid water loss from the grain. For the cultivars shown in Fig. 2, this corresponded to the period of grain desiccation; i.e. 32 DAA. This is consistent with results of previous workers (Benetrix et al., 1994; Gupta et al., 1996). Woodman and Engledow (1924) found that the appearance of gluten properties corresponded to the beginning of grain desiccation. Stone and Nicolas (1996a) reported a strong correlation $(r=0.91, \mathrm{P}<0.01)$ between formation of large glutenins and grain desiccation. Carceller and Aussenac (1999) investigated this correspondence further by applying ventilation at $30^{\circ} \mathrm{C}$ to produce artificial desiccation, using the same pair of cultivars, Soissons and Thésée shown in Fig. 2. When this premature artificial desiccation was carried out during the cell enlargement phase, the formation of SDSinsoluble glutenin polymers was closely related with the process of water loss from the grain. Also, the insoluble glutenin and thus the MWD of Soissons were always higher than Thésée for the same physiological stage.

\subsection{Interpretation of allelic effects}

One of the questions in relation to the effects of allelic variation of HMW-GS has been that, where two subunits are expressed at a locus, whether the effects on dough strength are predominantly due to one of the subunit pair or whether both subunits contribute. Evidence points to one of the subunits being predominant and, in each case, it is the x-type HMW-GS. For example, the evidence points to the HMW-GS $5(1 D x 5)$ as the individual subunit of the $5+10$ pair that is the major contributor to dough strength (Lafiandra et al., 1993; Blechl et al., 2007). 
This subunit contains an additional cysteine residue in the first repeat block adjacent to the Nterminal domain (Anderson and Greene, 1989). Table 1 shows results for UPP and dough strength for three pairs of biotypes from wheat lines that show contrasting behaviour (Pirozi et al., 2008). In each case, the line with higher UPP and dough strength has an x-type HMW-GS with a higher number of cysteine residues. Avocet A has subunit 5 with the additional cysteine while subunits 26 (Fiorello) and 20x (Halberd) each have only two cysteine residues which is two less than subunit 1Bx7 (Margiotta et al., 2000).

Can these chemical differences between HMW-GS provide an explanation for the type of behaviour shown in Fig. 3? That is, how might the earlier polymerization and higher MWD of some lines at maturity be explained in terms of differences in their HMW-GS and how might this then explain the empirical HMW-GS scores introduced by Payne and co-workers. The polymerization of glutenin subunits involves an oxidation process in which two $\mathrm{S}-\mathrm{H}$ (sulfhydryl) groups join to form an S-S (disulfide) bond. If we consider the polymerization of glutenin subunits as a simple chemical reaction in which the S-H groups of the HMW-GS are the reactants and the S-S bonds are the products, then

$\mathrm{S}-\mathrm{H}+\mathrm{S}-\mathrm{H} \rightarrow \mathrm{S}-\mathrm{S}$

And the polymerization rate is given by:

Rate $=k . f[\mathrm{~S}-\mathrm{H}]$

where $k$ is the rate constant and $f[\mathrm{~S}-\mathrm{H}]$ is a function of the concentration of cysteine groups. The particular function depends on the order of the reaction. This has not been determined for this reaction. However, it follows that the rate should be directly proportional to some function of the $\mathrm{S}-\mathrm{H}$ concentration. This agrees with the results shown in Table 1 where lines withHMW-GS having extra cysteines show more rapid polymerization.

\section{Polymerization studies of glutenin during grain development: Environmental effects}

During grain development, many environmental effects may influence final quality. These include availability of nutrients (e.g. nitrogen, sulphur), heat and drought stress and rain and frost damage. Here, we will focus on sulphur availability and heat stress, both of which have been shown to exert their effects through their influence on the polymerization of glutenin.

\subsection{Sulphur availability}

Although a survey in the early 1980s showed no evidence of sulphur deficiency in wheat (Byers et al., 1987), there has been mounting evidence since then that this may be an increasing problem in many areas around the world (Kettlewell et al., 1998). Some of the reasons for this are thought to be (a) a trend to use fertilizers not containing sulphur, (b) lower deposition of sulphur from industries in response to stricter pollution controls and (c) more intense cropping (e.g. high nitrogen application) that removes more sulphur from the soil (Naeem and MacRitchie, 2003). Sulphur deficiency can lead to lower grain yield as well as lower processing quality. It has been 
suggested that the critical value in terms of yield for sulphur deficiency in wheat is $1.2 \mathrm{mg} / \mathrm{g}$ and for the N:S ratio is 17:1 (i.e. below grain $\mathrm{S}$ levels of $1.2 \mathrm{mg} / \mathrm{g}$ and above $\mathrm{N}: \mathrm{S}$ ratios of 17:1, there are reductions in yield). Similar threshold values are thought to apply to effects on processing quality. Sulphur deficiency produces bucky dough properties; i.e. increased dough mixing requirements with increased dough resistance to stretching and reduced extensibility (Wrigley et al., 1984). These effects are explained by a shift in the MWD of glutenin to higher values caused by changes in composition.

Wheat proteins can be classified into S-rich and S-poor proteins (Shewry et al., 1986). The S-rich proteins include albumins, globulins, $\alpha$-, $\beta$ - and $\gamma$-gliadins and LMW-GS. The S-poor proteins are the $\omega$-gliadins and HMW-GS. When sulphur availability decreases, the S-poor proteins increase at the expense of the S-rich proteins. Of most relevance is that the ratio of HMWGS/LMW-GS increases. MacRitchie and Gupta (1993) reported a close relationship between the HMW-GS/LMW-GS ratio and UPP $(r=0.699)$ in flours from a set of 24 samples of the wheat variety Olympic, grown at different $\mathrm{S}$ fertilizer levels. The HMW-GS/LMW-GS ratio varied between 0.2 and 0.9 for these samples. By analyzing only one variety, it was possible to avoid any effects due to genetic variation. The relationship has been confirmed by collecting fractions of glutenin from SE-HPLC and showing that the HMW-GS/LMW-GS ratio increases, as the MW of glutenin increases (Larroque et al., 1997). Thus, the change in balance of dough properties (higher strength, lower extensibility) which is accentuated as the S deficiency becomes more acute, is caused by the shift in MWD to higher MWs.

\subsection{Heat stress}

Inconsistency of quality can be a problem for processors in the wheat industry. It may lead to high costs associated with having to adjust variables (e.g. mill and bakery settings) to compensate for the variations. These variations can result from seasonal conditions or from different growing locations. One of the greatest environmental effects, at least in certain regions, is heat stress. This occurs when the crop is subjected to high temperatures during grain filling, particularly in the period just before harvest. As discussed above, this is the period (grain desiccation) when post-translational glutenin polymerization proceeds most rapidly. Any effects which impinge on this process may have a serious influence on final quality. We have considered one variable, S deficiency that could increase in relevance in the future. Similarly, heat stress could also become more important in the future if predictions of global warming are correct. Heat stress is known to cause loss of yield and lowering of quality. Finney and Fryer (1958) reported these effects for wheat grown in the Great Plains area of the U.S., showing a decrease in dough strength and bread-making performance. The effects have been confirmed in studies by Blumenthal et al. (1993) and Stone and Nicolas (1994). It has been reported that dough strength increased as daily mean temperatures increased up to 30 _ during grain filling, and then decreased as temperatures increased above 30 _C (Randall and Moss, 1990; Dupont and Altenbach, 2003). Evidence has been reported that the effect of heat stress is to cause a reduction in the size of glutenin polymers (Blumenthal et al., 1995a; Ciaffi et al., 1996; Stone and Nicolas, 1996b). This effect has not been explained. It is believed that other proteins including chaperones such as BiP (binding protein) and foldases such as PDI (protein disulphide isomerase) may play a role in protein synthesis during grain filling (Dupont et al., 1998). Glutathione status may possibly be relevant as discussed by Rhazi et al. (2003). It may also be that the decreased 
formation of large glutenin polymers is simply due to a physical effect on the polymerization reaction.

A study of the effects of different temperature regimes on polymeric proteins during grain development has been reported by Irmak et al. (2008). The near-isogenic lines of Lance A (Glu$D 1 a$ allele: HMW-GS $2 *, 17+18,2+12$ ) and Lance C (Glu-D1d allele: HMW-GS 2*, 17+18, $5+10)$ were grown in greenhouse and growth chamber conditions. The results are summarized in Table 2. Three different regimes were used and the experiments were replicated in two different years, 2001 and 2002. The three temperature regimes used were:

1. Temperature maintained at $20 / 16^{\circ} \mathrm{C}$ (day/night) throughout (control)

2. Temperature maintained at $20 / 16^{\circ} \mathrm{C}$ until 25 DAA when a temperature of $35 / 20^{\circ} \mathrm{C}$ (2001) or $40 / 25^{\circ} \mathrm{C}(2002)$ was applied for $72 \mathrm{~h}$, followed by a return to $20 / 16^{\circ} \mathrm{C}$ until maturity.

3. Temperature maintained at $20 / 16^{\circ} \mathrm{C}$ until $25 \mathrm{DAA}$ when a temperature of $40 / 25^{\circ} \mathrm{C}$ was applied and maintained to maturity.

The experiment was intended to simulate conditions in the field where heat stress may involve short bursts (regime 2 ) or pronged periods (regime 3 ) of high temperature. In summary, the results showed, based on the relationship between UPP and MWD:

1. The line Lance $\mathrm{C}$ (Glu-D1d variant) began to form large polymers earlier by several days and reached higher values at maturity than Lance A (Glu-D1a variant), as noted above.

2. Heat stress caused a lowering of the MWD at maturity for both allelic variants although the effect was greater for the prolonged heat stress as would be expected.

3. The reduction in MWD by heat stress appeared to be less for the Glu-D1d line than the Glu-D1a line. For example, prolonged heat stress caused a reduction in UPP at maturity of about 12\% in 2001 and $6 \%$ in 2002 for the Glu-D1d allelic variant. By contrast, the corresponding reduction for the Glu-D1a allelic variant was about $21 \%$ in both years. This suggests that the Glu-D1d allele confers greater tolerance to heat stress than the GluD1a allele.

\section{General conclusions}

Polymerization of glutenin subunits is a post-translational process that occurs during the late stage of grain development when there is a rapid loss of water from the grain (grain desiccation stage). Glutenins from wheat lines with HMW-GS associated with dough strength (e.g. 5+10 at Glu-D1 and 7+9 at Glu-B1) start to polymerize earlier and reach higher MWs than lines with HMW-GS associated with dough weakness (e.g. 2+12 at Glu-D1 and 20x +20y at Glu-B1). The faster polymerization may be explained by a higher concentration of S-H groups as reactants in the formation of S-S bonds in the polymerization reaction. Sulphur deficiency results in an increase in the HMW-GS/LMW-GS ratio causing a shift in MWD to higher MW and this leads to bucky dough properties (i.e. higher resistance to extension and lower extensibility). If sulphur deficiency is anticipated to rise in certain areas, wheat breeders may need to consider breeding varieties which give lower dough strength and higher extensibility under normal conditions of Savailability. Heat stress produces a decrease in dough strength, as reported by a number of 
workers. The decrease is caused by an effect on the polymerization of glutenin, leading to lower MWs at maturity. A near-isogenic line with dough strength associated HMW-GS was more tolerant to heat stress than its allelic counterpart with HMW-GS associated with dough weakness. This confirms results reported by Blumenthal et al. (1995b) which showed that lines with the Glu-D1d allele were less susceptible to heat stress than lines with the Glu-D1a allele. The interaction between the timing of polymerization and the timing of the heat stress may be critical to the different responses of genotypes. For example, a genotype for which there is appreciable formation of large polymers before the application of high temperatures will be less susceptible than a genotype in which polymerization is delayed. If global temperatures are predicted to rise in the future, the HMW-GS composition may need to be adjusted towards greater strength so as to impart higher tolerance to the expected effects of heat stress.

\section{References}

Anderson, O.D., Green, F.C. 1989. The characterization and comparative analysis of high-molecularweight glutenin genes from genomes $A$ and $B$ of a hexaploid bread wheat. Theoretical and Applied Genetics 77, 689-700.

Bean, S.R., Lyne, R.K., Tilley, K.A., Chung, O.K., Lookhart, G.L. 1998. A rapid method for quantitation of insoluble polymeric proteins in flour. Cereal Chemistry 75, 374-379.

Benetrix, F., Kaan, F., Autran, J.-C. 1994. Changes in protein complexes of durum wheat in developing seed. Crop Science 34, 462-468.

Blechl, A.E., Lin, J.W., Nguyen, S.R., Anderson, O.D., Dupont, F.M. 2007. Transgenic wheats with elevated levels of Dx5 and/or Dy10 high-molecular-weight glutenin subunits yield dough with increased mixing strength and tolerance. Journal of Cereal Science 45, 172-183.

Blumenthal, C., Barlow, E.W.R., Wrigley, C.W. 1993. Growth environment and wheat quality: The effect of heat stress on dough properties and gluten proteins. Journal of Cereal Science 19, 3-21.

Blumenthal, C., Bekes, F., Gras, P.W., Barlow, E.W.R., Wrigley, C.W. 1995a. Identification of wheat genotypes tolerant to the effects of heat stress on grain quality. Cereral Chemistry 72, 539-544.

Blumenthal, C., Gras, P.W., Bekes, F., Barlow, E.W.R., Wrigley, C.W. 1995b. Possible role for the Glu-D1 locus with respect to tolerance to dough-quality change after heat stress. Cereal Chemistry 72 , 135-136.

Byers, M., McGrath, S.P., Webster, R.1987. A survey of the sulphur content of wheats grown in Britain. Journal of the science of Food and Agriculture 38, 151-160. 
Carceller, J.L., Aussenac, T. 1999. Accumulation and changes in molecular size distribution of polymeric proteins in developing grain of hexaploid wheats: role of the desiccation phase. Australian Journal of Plant Physiology 26, 301-310.

Carceller, J.-L , Aussenac, , T. 2001. Size characterization of glutenin polymers by HPSEC-MALLS. Journal of Cereal Science 33, 131-142.

Ciaffi, M., Tozzi, L., Borghi, B., Corbellini, M., Lafiandra, D. 1996. Effects of heat shock during grain filling on the gluten protein composition of bread wheat. Journal of Cereal Science 24, 91-100.

Daniel, C., Triboi, E. 2002. Changes in wheat protein aggregation during grain development: effects of temperature and water stress. European Journal of Agronomy 16, 1-12.

Gobin, P., Ng, P.K.W., Buchanan, B.B., Kobrehel, K. 1997. Sulfhydryl-disulfide changes in proteins of developing wheat grain. Physiology and Biochemistry 35, 777-783.

Finney, K.F., Fryer, H.C. 1958. Effect on loaf volume of high temperatures during the fruiting period of wheat. Agronomy Journal 50, 28-34.

Gupta, R.B., MacRitchie, F. 1994. Allelic variations of glutenin subunit and gliadin loci, Glu-1, HGlu-3 and Gli-1 of common wheats. II. Biochemical basis of the allelic effects on dough properties. Journal of Cereral Science 19, 19-29.

Gupta, R.B., Khan, K, MacRitchie, F. 1993. Biochemical basis of flour properties inbread wheats. I. Effects of variation in quantity and size distribution of polymeric proteins. Journal of Cereal Science18, 23-41.

Gupta, R.B., Masci, S., Lafiandra, D., Bariana, H.S., MacRitchie, F. 1996. Accumulation of protein subunits and their polymers in developing grains of hexaploid wheats. Journal of Experimental Botany 47 1377-1385.

Huebner, F.R., Kaczkowski, J., Bietz, J.A. 1990. Quantitative variation of wheat proteins from grain at different stages of maturity and from different spike locations. Cereal Chemistry 67, 464-470.

Irmak, S., Naeem, H.A., Lookhart, G.L., MacRitchie, F. 2008. Effect of heat stress on wheat proteins during kernel development in wheat near-isogenic lines differing at Glu-D1. Journal of Cereal Science 48, 513-516.

Johansson, E., Oscarson, P., Heneen, W.K., Lundborg, T. 1994. Differences in accumulation of storage proteins between wheat cultivars during development. Journal of the Science of Food and Agriculture 64, 305-313.

Kettlewell, P.S., Griffiths, M.W., Hocking, T.J., Wallington, D.J. 1998. Dependence of wheat dough extensibility on flour sulphur and nitrogen concentrations and the influence of foliar-applied sulphur and nitrogen fertilizers, Journal of Cereal Science 28, 15-23. 
Lafiandra, D., D’Ovidio, R., Porceddu, E., Margiotta, B., Colaprico, G. 1993. New data supporting high Mr glutenin subunit 5 as the determinant of quality differences among the pairs $5+10$ vs. $2+12$. Journal of Cereal Science 18, 197-206.

Larroque, O.R., Gianibelli, M.C., Batey, I.L., MacRitchie, F. 1997. Electrophoretic characterization of fractions collected from gluten protein extracts subjected to size-exclusion high=performance liquid chromatography. Electrophoresis 18, 1064-1067.

MacRitchie, F. 2010. Concepts in Cereal Chemistry. CRC Press Taylor and Francis Group, Boca Raton, U.S.A. pp 86-88.

MacRitchie, F., Gupta, R.B. 1993. Functionality-composition relationships of wheat flour as a result of variation in sulfur availability. Australian Journal of Agricultural Research 44, 1767-1774.

Margiotta, B., Pfluger, L., Roth, M.R., MacRitchie, F., Lafiandra, D, 2000. Isogenic bread wheat lines differing in number and type of high Mr glutenin subunits. In: "Wheat Gluten" (P.R. Shewry and A.S. Tatham, eds). Royal Society of Chemistry, London, pp 29-33.

Naeem, H.A., MacRitchie, F. 2003. Effect of sulphur nutrition on agronomic and quality attributes of wheat. In: Sulphur in Plants (Y.P. Abrol and A. Ahmad, eds), Kluwer Academic Publishers, The Netherlands, pp 305-322.

Naeem, H.A., MacRitchie, F. 2005. Polymerization of glutenin during grain development in near-isogenic wheat lines differing at Glu-D1 and Glu-B1 in greenhouse and field. Journal of Cereal Science 41, 7-12.

Panozzo, J.F., Eagles, H.A., Wootton, M. 2001. Changes in protein composition during grain development in wheat. Australian Journal of Agricultural Research 52, 485-493.

Paulon, D. 2000. Protein composition in developing grain of near-isogenic lines. MS thesis, Kansas State University, Manhattan, Kansas.

Pirozi, M.R., Margiotta, B., Lafiandra, D., MacRitcie, F. 2008. Composition of polymeric proteins and bread-making quality of wheat lines with allelic HMW-GS differing in number of cysteines. Journal of Cereal Science 48, 117-122.

Payne, P.I., Corfield, K.G., Holt, L.M., Blackman, J.A. 1981. Correlations between the inheritance of certain high-molecular weight subunits of glutenin and bread-making quality in progenies of six crosses of bread wheat. Journal of the Science of Food and Agriculture 32, 51-60.

Randall, P.J., Moss, H.J. 1990. Some effects of temperature regime during grain filling on wheat quality. Australian Journal of Agricultural Reszearch 41, 603-617.

Rhazi, L., Cazalis, R., Lemelin., E., Aussenac, T. 2003. Changes in the glutathione thiol-disulfide status during wheat grain development. Plant Physiology and Biochemistry 41, 895-902. 
Shewry, P.R., Tatham, A.S., Forde, J., Kreis, M., Miflin, B.J. 1986. The classification and nomenclature of wheat gluten proteins: a reassessment. Journal of Cereal Science 4, 97-106.

Stone, P.J., Nicolas, M.E. 1994. Wheat cultivars vary widely in their response of grain yield and quality to short periods of post-anthesis heat stress. Australian Journal of Plant Physiology 21, 887-900.

Stone, P.J., Nicolas, M.E. 1996a. Varietal differences in mature protein composition of wheat resulted from different rates of polymer accumulation during grain filling. Australian Journal of Plant Physiology 23, 727-737.

Stone, P.J., Nicolas, M.E. 1996b. Effect of timing of heat stress during grain filling on two wheat varieties differing in heat tolerance. II. Fractional protein accumulation. Australian Journal of Plant Physiology 23, 739-749.

Weegels, P.L., Hamer, R.J., Schofield, J.D. 1997. Depolymerization and repolymerization of wheat gluten during dough processing. I. Relationships between glutenin macropolymer content and quality parameters. Journal of Cereal Science 23, 103-111.

Woodman, H.E., Engledow, F.I. 1924. A chemical study of the development of the wheat grains. Journal of Agricultural Science 14, 563-586.

Wrigley, C.W., Du Cros, D.L.,Fullington, J.G., Kasarda, D.D. 1984. Changes in polypeptide composition and grain quality due to sulfur deficiency in wheat. Journal of Cereal Science 2, 15-24. 
Figures and Tables

Figure 1. Chromosomal location of genes coding for gluten proteins (MacRitchie and Lafiandra, 1997).

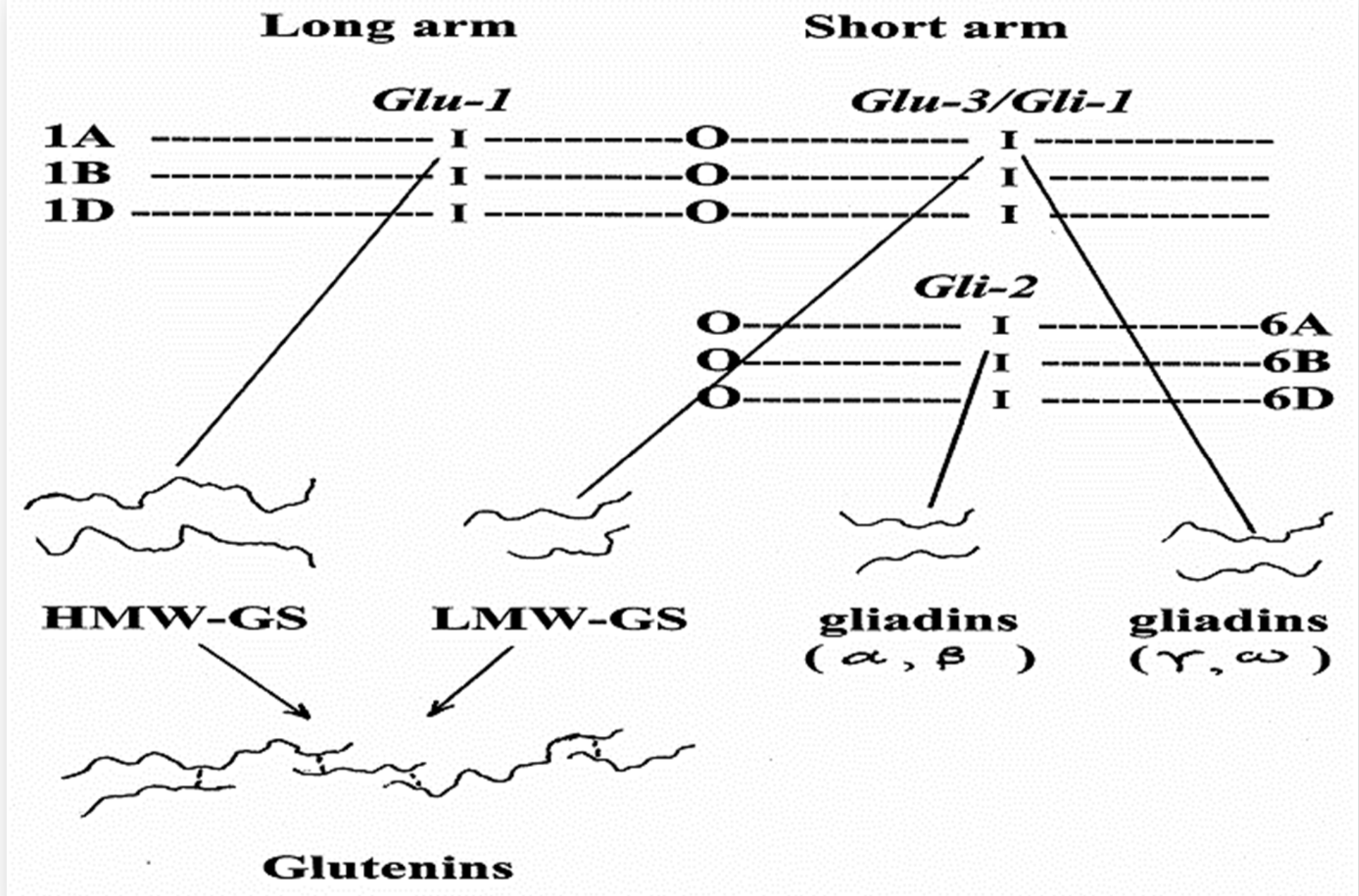


Figure 2. Evolution of the quantity of the different fractions (mg per kernel) for (a) Soissons and (b) Thésée, as a function of days after anthesis. $\boldsymbol{\Delta}$ insoluble polymers; $O$ soluble polymer; $\square$ albumins and globulins; $\Delta$ monomers and $\square$ total proteins. Stages: P1, cell division; P2, cell enlargement; and P3, dehydration and grain maturation (Carceller and Aussenac, 1999).

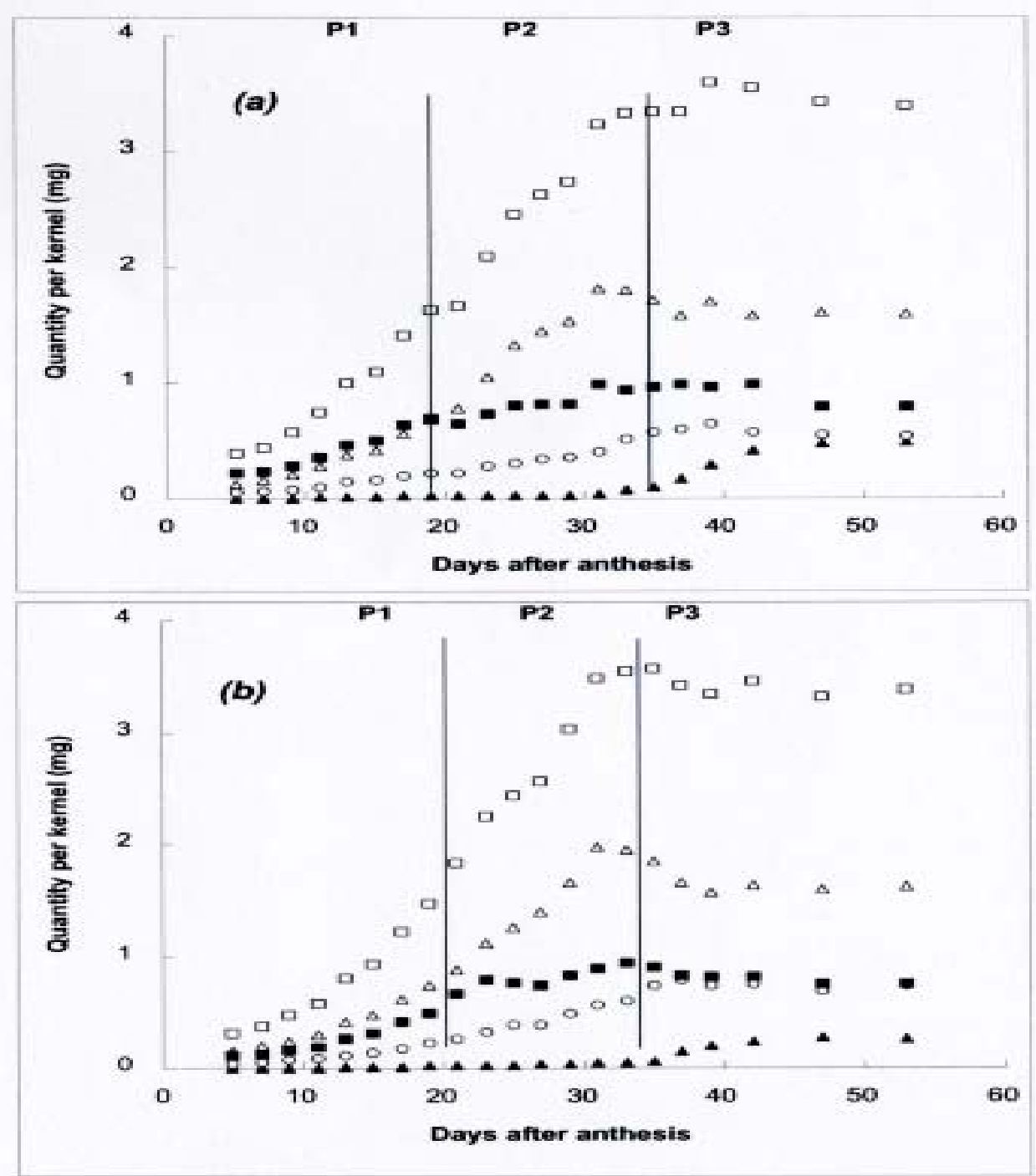


Figure 3. UPP vs. DAA for Avocet A (open squares) and Avocet B (closed squares) from greenhouse planting in year 2001(Naeem and MacRitchie, 2005).

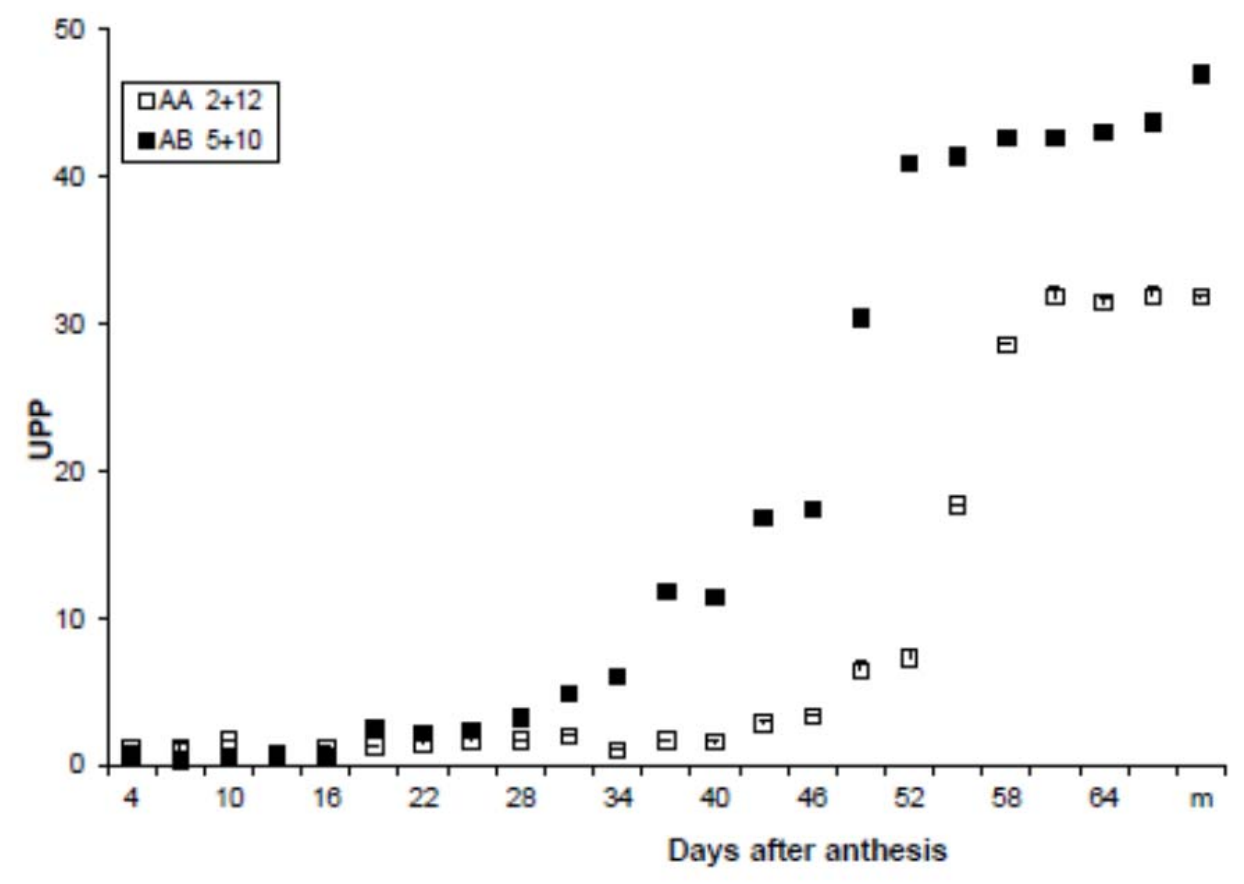


Table 1. High molecular weight glutenin subunits with different number of cysteines (Pirozi et al, 2008).

\begin{tabular}{lccccc}
\hline $\begin{array}{l}\text { Lines and their } \\
\text { biotypes }\end{array}$ & \multicolumn{3}{c}{ HMW-GS composition } & \%UPP & $\begin{array}{l}\text { Peak Force } \\
\text { (g) }\end{array}$ \\
\hline & A & B & D & & \\
\cline { 2 - 6 } Avocet A & - & $7+8$ & $5+10$ & 39.3 & 17.5 \\
Avocet b & - & $7+8$ & $2+12$ & 33.9 & 8.4 \\
Fiorello & 1 & $7+8$ & $5^{*}+12$ & 40.0 & 13.6 \\
Fiorello & 1 & $26+27$ & $5^{*}+12$ & 28.6 & 9.3 \\
Halberd & 1 & $7+9$ & $5+10$ & 40.9 & 15.1 \\
Halberd & 1 & $20 x+20 y$ & $5+10$ & 36.0 & 11.7 \\
\hline
\end{tabular}

Table 2. Data for near-isogenic lines of Lance for different temperature regimes (Irmak et al, 2008).

\begin{tabular}{|c|c|c|c|c|c|c|}
\hline \multirow{2}{*}{$\begin{array}{l}\text { Lance } \\
\text { lines }\end{array}$} & \multirow{2}{*}{$\begin{array}{l}\text { Temperature } \\
\text { regime }\end{array}$} & \multicolumn{3}{|c|}{2001} & \multicolumn{2}{|c|}{2002} \\
\hline & & $\begin{array}{l}\text { Time \%UPP starts } \\
\text { steep increase } \\
\text { (DAA) }\end{array}$ & $\begin{array}{l}\text { \%UPP at } \\
\text { Maturity }^{\mathrm{a}}\end{array}$ & $\begin{array}{l}\text { \%SDS-Sed. } \\
\text { volume }^{\text {b }}\end{array}$ & $\begin{array}{l}\text { Time \%UPP } \\
\text { starts steep } \\
\text { increase (DAA) }\end{array}$ & $\begin{array}{l}\text { \%UPP at } \\
\text { Maturity }^{a}\end{array}$ \\
\hline C & 1 & 25 & 51 & 4.7 & 25 & 48 \\
\hline A & 1 & 31 & 43 & 4.1 & 28 & 42 \\
\hline C & 2 & 25 & 47 & 3.0 & 22 & 47 \\
\hline A & 2 & 31 & 37 & 1.2 & 25 & 41 \\
\hline C & 3 & 19 & 45 & 1.4 & 19 & 45 \\
\hline A & 3 & 22 & 34 & 1.0 & 25 & 33 \\
\hline
\end{tabular}

${ }^{\mathrm{a}}$ LSD values for \%UPP of the three treatments over 2 years were less than $0.5 \%$.

${ }^{\mathrm{b}}$ LSD value for SDS-Sedimentation test was $0.12 \mathrm{~mL}$. 